\title{
Enraizamento de estacas lenhosas de pessegueiro cv. Okinawa em diferentes diâmetros de ramos, substratos e recipientes
}

\author{
Rooting of peach cv. Okinawa hardwood cuttings at different \\ stem diameters, substrates, and pots
}

\author{
Mauro Brasil Dias Tofanelli ${ }^{1}$ João Domingos Rodrigues ${ }^{2}$ Elizabeth Orika Ono $^{3}$
}

\section{RESUMO}

O trabalho foi desenvolvido no Departamento de Produção Vegetal - Setor Horticultura da Faculdade de Ciências Agronômicas (FCA) da Universidade Estadual Paulista "Júlio de Mesquita Filho” (UNESP), Campus de Botucatu (SP) com o objetivo de avaliar a influência de diferentes substratos e tipos de recipientes no potencial de enraizamento de estacas lenhosas de pessegueiro cultivar Okinawa com diferentes diametros. As estacas foram tratadas com $2,5 \mathrm{~g} \mathrm{~L}^{-1}$ de ácido indol-butírico. $O$ período de permanência das estacas na casa de vegetação foi de 50 dias. Os tratamentos consistiram de seis substratos: areia, casca de arroz carbonizada, vermiculita, areia + casca de arroz carbonizada, areia + vermiculita e casca de arroz carbonizada + vermiculita, com as misturas na proporção $1: 1 v / v$, três tipos de recipientes: sacos plásticos, bandejas de poliestireno expandido e bandejas plásticas e dois grupos de estacas com diâmetros diferentes: 2 a $6 \mathrm{~mm}$ e 6 a $10 \mathrm{~mm}$. O melhor resultado de enraizamento foi obtido em sacos plásticos com vermiculita independente do diâmetro das estacas.

Palavras-chave: Prunus persica, propagação vegetativa, estaquia, raizes adventícias, diâmetro de estaca.

\section{ABSTRACT}

This work was carried out at the Department of Plant Production/Horticulture of the Faculdade de Ciencias Agronomicas (FCA) of the Universidade Estadual Paulista (UNESP) located in Botucatu (SP, Brazil). The purpose of this study was to evaluate the influence of substrate and pot type on rooting of stem hardwood cuttings of peach cultivar Okinawa with different diameters. The cuttings were treated with $2.5 \mathrm{~g} \mathrm{~L}^{-1}$ of IBA. The cuttings were maintained in greenhouse for 50 days. The treatments consisted of the combination of six substrate compositions: sand, carbonized rice husk, vermiculite, sand + carbonized rice husk, sand + vermiculite, and carbonized rice husk + vermiculite, mixture at proportion $1: 1 \mathrm{v} / \mathrm{v}$ and three types of pots: plastic bags, polystyrene trays, plastic trays and two groups of cutting diameter: 2 to $6 \mathrm{~mm}$ and 6 to $10 \mathrm{~mm}$. The highest rooting frequency was obtained with plastic bag, and vermiculite independent of cutting diameter.

Key words: Prunus persica, vegetative propagation, rooting, adventitious root, cutting diameter.

\section{INTRODUÇÃO}

O pessegueiro (Prunus persica (L.) Batsch.) é uma importante frutífera de clima temperado no cenário mundial, sendo no Brasil cultivado, principalmente, na região Sul. Em outros estados brasileiros, como São Paulo, a área explorada com esta espécie tem crescido nos últimos anos, saltando de 1.470ha colhidos em 1988 para 1.954 ha em 1998 (AGRIANUAL, 1999; AGRIANUAL, 2001). A expansão dos plantios desta espécie depende de vários fatores que possibilitariam atingir patamares ainda maiores e, dentre estes fatores, a produção de mudas de qualidade e de baixo custo contribuiria, notavelmente, para o

\footnotetext{
'Engenheiro Agrônomo, Doutorando em Agronomia/Fitotecnia, Departamento de Produção Vegetal/Horticultura, FCA/UNESP, Fazenda Experimental Lageado, CP 237, 8603-970, Botucatu, SP. Email: maurobdt@bol.com.br. Autor para correspondência. ${ }^{2}$ Engenheiro Agrônomo, Professor Titular, Doutor, Departamento de Botânica, IBB/UNESP, CP 510, 18618-000, Botucatu, SP. ${ }^{3}$ Biólogo, Professor, Doutor, Departamento de Botânica, IBB/UNESP, CP 510, 18618-000, Botucatu, SP.
} 
aumento de plantios e da produção de pêssego (CHALFUN \& HOFFMANN, 1997).

O pessegueiro é propagado, principalmente, por meio da enxertia de borbulhas de cultivares-copa em porta-enxertos oriundos de sementes (CHALFUN et al., 1994, TONIETTO et al., 1997). A cultivar de pessegueiro Okinawa é o porta-enxerto mais utilizado nos estados como São Paulo e Minas Gerais, devido principalmente, a sua resistência à maioria dos nematóides do gênero Meloidogyne (NACHTIGAL \& PEREIRA, 2000). Este método convencional de propagação do pessegueiro apresenta alguns inconvenientes, como maior necessidade de mão-deobra especializada, maior custo, maior tempo para obtenção das mudas e risco de segregação genética dos porta-enxertos (5\%) em relação aos progenitores (CHALFUN \& HOFFMANN, 1997, TOFANELLI et al., 1997). A estaquia, então, poderia auxiliar na melhoria da tecnologia de produção de mudas de pessegueiro. No entanto, este método de propagação não tem sido uma alternativa viável para o pessegueiro, devido a alguns entraves, como principalmente a baixa capacidade de enraizamento de estacas caulinares apresentada pela maioria das cultivares plantadas no Brasil (TOFANELLI, 1999).

O uso de algumas tecnologias poderia melhorar tanto a qualidade da muda quanto a porcentagem de enraizamento e a qualidade das estacas enraizadas (AVERY \& BEYL, 1991). Dentre estas, poderse-ia citar o uso de substratos e recipientes mais adequados para proporcionarem maior enraizamento, melhor distribuição e conformação das raízes (HARTMANN et al., 1997; OFORI et al., 1996, KLEIN et al., 2000).

De acordo com HOFFMANN et al. (1996), o substrato destina-se a sustentar as estacas durante o período de enraizamento, mantendo sua base em ambiente úmido, escuro e suficientemente aerado. Os mesmos autores também relataram algumas características importantes que um recipiente para produção de mudas deve possuir e que poderiam ser estendidas aos recipientes indicados para estaquia, como, por exemplo, acondicionar o volume adequado de substrato, possuir bom sistema de drenagem, possuir boa retenção do substrato, possuir boa retenção de umidade e ter baixo custo de aquisição. Outro fator que afeta o potencial de enraizamento é o diâmetro da estaca, pois segundo FACHINELLO et al. (1995), o diâmetro ideal depende, principalmente, da espécie e do tipo de estacas, no caso das lenhosas, variaria entre 6 a $25 \mathrm{~mm}$.

O presente trabalho teve como objetivo avaliar a capacidade de formação de raízes em estacas de ramos lenhosos de pessegueiro cv. Okinawa em dois diâmetros distintos, utilizando-se diferentes substratos e recipientes.

\section{MATERIAL EMÉTODOS}

O experimento foi conduzido no Departamento de Produção Vegetal - Setor Horticultura da Faculdade de Ciências Agronômicas (FCA), da Universidade Estadual Paulista "Júlio de Mesquita Filho" (UNESP), Campus de Botucatu (SP) no período de julho a agosto de 2001.

Ramos lenhosos de plantas matrizes de pessegueiro foram coletados do pomar da Coordenadoria de Assistência Técnica Integral (CATI) localizada no município de Itaberá (SP). As estacas foram preparadas desses ramos lenhosos com 10 a $15 \mathrm{~cm}$ de comprimento e diâmetros de 2 a $6 \mathrm{~mm}$ e de 6 a $10 \mathrm{~mm}$. Todas as estacas foram tratadas com $2.5 \mathrm{~g} \mathrm{~L}^{-1} \mathrm{de}$ ácido indol-butírico (IBA) durante cinco segundos, logo após o preparo das mesmas. Após a aplicação do IBA, as estacas foram plantadas e colocadas em casa de vegetação por 50 dias, quando foi efetuada a coleta de dados. A temperatura na casa de vegetação foi de $25 \pm 9^{\circ} \mathrm{C}$ e a umidade relativa de $80 \%$. A umidade foi mantida por aspersão num turno de rega de 10 minutos diários.

Os substratos utilizados foram areia grossa lavada, casca de arroz carbonizada, vermiculita, e as misturas areia + vermiculita, areia + casca de arroz carbonizada e vermiculita + casca de arroz carbonizada na proporção 1:1v/v. Esses substratos foram colocados em três tipos de recipientes: sacos plásticos pretos de polietileno de $15 \times 10 \mathrm{~cm}$, bandejas de poliestireno expandido de 72 células e bandejas plásticas de $60 \times 27 \times 9,5 \mathrm{~cm}$ com 14 orifícios de $1,9 \mathrm{~cm}$ de diâmetro no fundo para drenagem do excesso de água.

O delineamento experimental adotado foi inteiramente casualizado com 3 repetições e 14 estacas por parcela, sendo metade delas apresentando diâmetro de 2 a $6 \mathrm{~mm}$ e a outra metade de 6 a $10 \mathrm{~mm}$, num esquema fatorial $6 \times 3 \times 2$, constituído de seis tipos de substratos, três tipos de recipientes e dois diâmetro de estacas.

As variáveis analisadas neste trabalho foram porcentagem de estacas enraizadas, sendo consideradas as estacas que apresentassem pelo menos uma raiz adventícia emitida, porcentagem de estacas com brotos, número médio de raízes primárias formadas por estaca enraizada e comprimento médio da maior raiz formada por estaca enraizada.

As análises estatísticas foram realizadas comparando-se as médias pelo teste Duncan com nível de significância de 5\%. Efetuou-se a

Ciência Rural, v. 33, n. 3, mai-jun, 2003. 
transformação de dados segundo a equação arco seno $\sqrt{x / 100}$ para os dados em porcentagem e $\sqrt{x+1}$ para os valores quantitativos.

\section{RESULTADOS E DISCUSSÃO}

Observou-se o efeito significativo do recipiente, substrato e da interação entre diâmetro das estacas, recipiente e substrato no enraizamento de estacas lenhosas de pessegueiro. Não houve efeito do diâmetro sobre o potencial de enraizamento das estacas. O substrato vermiculita proporcionou maior enraizamento $(20,5 \%)$, embora tenha sido estatisticamente igual à areia (11,8\%) (Tabela 1). NACHTIGAL \& PEREIRA (2000) demonstraram que os melhores resultados de enraizamento de estacas herbáceas de pesseguerio cv. Okinawa coletadas de plantas jovens foram obtidos, quando utilizaram vermiculita fina ou média $(87,6 \%$ e $80,6 \%$, respectivamente) e atribuíram a estes resultados o melhor equilíbrio na relação água/ar apresentado pela vermiculita. Já DUTRA \& KERSTEN (1996) demonstraram que o substrato areia + serragem proporcionou os melhores porcentuais de enraizamento de estacas de ameixeira, cultivar Frontier, quando elas foram colhidas em janeiro e março $(68,22 \%$ e 65,99\%, respectivamente). Quanto ao efeito do recipiente no enraizameto, o saco plástico $(12,6 \%)$ e a bandeja de poliestireno expandido $(10,0 \%)$ foram superiores à bandeja plástica (2,0\%) (Tabela 1). Observou-se que, nas bandejas plásticas, ocorreu menor drenagem da umidade do substrato, e esta, pode ter sido a principal causa para os menores resultados obtidos neste tratamento, pois o excesso de umidade e, conseqüentemente, a falta de oxigênio (anoxia), provocou a diminuição do porcentual de enraizamento de estacas. HOFFMANN et al. (1996) mencionaram que um bom recipiente para enraizamento apresenta algumas características tais como uma boa capacidade de drenagem. Devido à interação dos três fatores ter sido significativa, foi realizado desdobramento através do teste de médias (Tabela 1). Observou-se que o maior porcentual de enraizamento foi obtido com estacas de menor diâmetro em sacos plásticos utilizando-se vermiculita como substrato $(47,4 \%)$, no entanto, este resultado não foi estatisticamente superior aos obtidos nos tratamentos com estacas de maior diâmetro em sacos plásticos com vermiculita $(37,7 \%)$, com estacas de maior diâmetro em bandeja plástica com vermiculita $(28,6 \%)$ e com estacas de menor diâmetro em sacos plásticos com areia + vermiculita (17,1\%).

Para a variável brotação, verificou-se o efeito significativo dos fatores recipiente, substrato e diâmetro (Tabela 2), mas nenhuma das interações foi significativa. Para o fator recipiente, o maior porcentual de estacas brotadas foi obtido com bandeja de poliestireno expandido $(20,3 \%)$ e para o fator substrato, com vermiculita $(29,2 \%)$, areia $(26,0 \%)$ e areia + vermiculita $(20,4 \%)$. Estes resultados demonstram que, também para a variável brotação, o equilíbrio na relação água/ar promovido pela vermiculita e/ou areia e a capacidade de drenagem de cada recipiente foram favoráveis à formação de estacas brotadas. Já para a variável diâmetro, estacas mais espessas, apresentaram

Tabela 1 - Porcentagem de enraizamento de estacas lenhosas de pessegueiro cv. Okinawa. Médias em função dos fatores recipientes e substrato e da interação entre recipiente, substrato e diâmetro de estaca. FCA/UNESP, Botucatu, 2001.

\begin{tabular}{|c|c|c|c|c|c|c|c|c|}
\hline \multirow{3}{*}{$\begin{array}{c}\text { Diâmetro de } \\
\text { estaca }\end{array}$} & \multicolumn{6}{|c|}{ Fatores da interação } & \multirow{2}{*}{\multicolumn{2}{|c|}{ Médias }} \\
\hline & \multicolumn{5}{|c|}{ Substrato } & \multirow{2}{*}{$\frac{\text { Recipiente }}{\text { Ver+CC }}$} & & \\
\hline & $\mathrm{Ar}$ & Ver & $\mathrm{CC}$ & $\mathrm{Ar}+\mathrm{Ver}$ & $\mathrm{Ar}+\mathrm{CC}$ & & & \\
\hline$<\varnothing$ & $20,8 \mathrm{abA}$ & $6,5 \mathrm{cAB}$ & $1,7 \mathrm{aAB}$ & $0 \mathrm{cB}$ & $0 \mathrm{aB}$ & $0 \mathrm{bB}$ & BP1 & 2,0 \\
\hline$>\varnothing$ & $0 \mathrm{cB}$ & $28,6 \mathrm{abcA}$ & $1,7 \mathrm{aB}$ & $1,7 \mathrm{bcB}$ & $0 \mathrm{aB}$ & $0 \mathrm{bB}$ & $\mathrm{BPl}$ & \\
\hline$<\varnothing$ & $5,5 \mathrm{bcAB}$ & $6,5 \mathrm{cAB}$ & $14,3 \mathrm{aAB}$ & $16,2 \mathrm{abA}$ & $13,5 \mathrm{aAB}$ & $0 \mathrm{bB}$ & $\mathrm{BPe}$ & 10,0 \\
\hline$>\varnothing$ & $36,9 \mathrm{aA}$ & $9,7 \mathrm{bcAB}$ & $0 \mathrm{aB}$ & $6,5 \mathrm{abcAB}$ & $14,3 \mathrm{aAB}$ & $28,6 \mathrm{aA}$ & $\mathrm{BPe}$ & \\
\hline$<\varnothing$ & $9,7 \mathrm{abcBC}$ & $47,4 \mathrm{aA}$ & $0 \mathrm{aC}$ & $17,1 \mathrm{abAB}$ & $1,7 \mathrm{aBC}$ & $9,8 \mathrm{abBC}$ & $\mathrm{Sac}$ & 12,6 \\
\hline$>\varnothing$ & $17,7 \mathrm{abAB}$ & $37,7 \mathrm{abA}$ & $0 \mathrm{aC}$ & $33,2 \mathrm{aAB}$ & $6,5 \mathrm{abBC}$ & $18,7 \mathrm{aAB}$ & $\mathrm{Sac}$ & \\
\hline Médias & 11,8 & 20,5 & 1,2 & 9,1 & 3,6 & 4,8 & & \\
\hline CV $(\%)$ & & & & & & & & \\
\hline
\end{tabular}

Médias seguidas por letras distintas, minúsculas na mesma coluna e maiúsculas na mesma linha, diferem entre si pelo teste Duncan, em nível de $5 \%$ de significância.

BPl - bandeja plástica, Bpe - bandeja de poliestireno expandido, Sac - saco plástico, Ar - areia, Ver - vermiculita, CC - casca de arroz carbonizada, $<\varnothing$ - estaca com menor diâmetro, $>\varnothing$ - estaca com maior diâmetro. 
Tabela 2 - Porcentagem de estacas com brotos e número de raízes em estacas lenhosas de pessegueiro cv. Okinawa. Médias em função dos fatores recipiente, substrato e diâmetro de estaca. FCA/UNESP, Botucatu, 2001.

\begin{tabular}{|c|c|c|c|c|c|c|}
\hline Variável & Recipiente & & Substrato & & Diâmetro & \\
\hline \multirow{6}{*}{$\begin{array}{l}\text { Brotação } \\
(\%)\end{array}$} & BP1 & $7,8 b$ & $\mathrm{Ar}$ & $26,0 \mathrm{a}$ & $<\varnothing$ & $9,0 \mathrm{~b}$ \\
\hline & $\mathrm{BPe}$ & $20,3 a$ & Ver & $29,2 \mathrm{a}$ & $>\varnothing$ & $17,2 \mathrm{a}$ \\
\hline & $\mathrm{Sac}$ & $11,5 b$ & $\mathrm{CC}$ & $6,3 b$ & & \\
\hline & & & $\mathrm{Ar}+\mathrm{Ver}$ & $20,4 a$ & & \\
\hline & & & $\mathrm{Ar}+\mathrm{CC}$ & $1,1 b$ & & \\
\hline & & & Ver+CC & $6,7 b$ & & \\
\hline \multirow[t]{2}{*}{ CV (\%) } & & & 67,3 & & & \\
\hline & BPl & $1,1 b$ & $\mathrm{Ar}$ & $3,3 a b$ & $<\varnothing$ & 2,9 \\
\hline Número & $\mathrm{BPe}$ & $3,6 a$ & Ver & $5,4 \mathrm{a}$ & $>\varnothing$ & 2,0 \\
\hline de & $\mathrm{Sac}$ & $3,1 \mathrm{a}$ & $\mathrm{CC}$ & $0,9 \mathrm{c}$ & & \\
\hline \multirow[t]{3}{*}{ raízes } & & & $\mathrm{Ar}+\mathrm{Ver}$ & $2,8 \mathrm{abc}$ & & \\
\hline & & & $\mathrm{Ar}+\mathrm{CC}$ & $1,5 \mathrm{bc}$ & & \\
\hline & & & $\mathrm{Ver}+\mathrm{CC}$ & $1,9 b c$ & & \\
\hline CV $(\%)$ & & & 47,1 & & & \\
\hline
\end{tabular}

Médias seguidas por letras distintas na coluna diferem entre si pelo teste Duncan, em nível de 5\% de significância.

$\mathrm{BPl}$ - bandeja plástica, BPe - bandeja de poliestireno expandido, Sac - saco plástico, Ar - areia, Ver - vermiculita, CC - casca de arroz carbonizada, $<\varnothing$ estaca com menor diâmetro, $>\varnothing$ - estaca com maior diâmetro. maior porcentual de brotação, devido talvez, pela maior disponibilidade de reservas nas estacas com maior diâmetro, favorecendo a emissão dos brotos. FACHINELLO et al. (1995) mencionaram que, estacas com maior diâmetro apresentam maiores níveis de substâncias de reservas, favorecendo o enraizamento. No entanto, podem apresentar também altas taxas de brotações, prejudicando a formação de raízes.

Houve efeito do recipiente e do substrato no número de raízes por estaca enraizada (Tabela 2), e não houve efeito significativo do diâmetro e nem das interações entre os fatores. Os tratamentos bandeja de poliestireno expandido (3,6 raízes) e saco plástico ( 3,1 raízes) foram superiores à bandeja plástica (1,1 raiz). Já o substrato vermiculita promoveu maior número de raízes $(5,4$ raízes), embora tenha sido estatisticamente equivalente à areia $(3,3$ raízes) e à mistura areia + vermiculita $(2,8$ raízes). MESÉN et al. (1997) estudaram o enraizamento de estacas da espécie arbórea Cordia alliodora (RUTZ \& PAVON) utilizando-se areia, cascalho e serragem como substrato e observaram que, os dois primeiros apresentaram maior número de raízes devido a melhor porosidade e a relação oxigênio/água disponível nestes substratos.

Para a variável comprimento de raiz, houve efeito do recipiente, substrato e da interação destes e não houve efeito significativo do diâmetro de estaca e das demais interações dos fatores (Tabela 3). Os maiores comprimentos obtidos nas bandejas de poliestireno expandido e nos sacos plásticos podem ser explicados pela maior disponibilidade de área para o crescimento das raízes em profundidade nestes recipientes, pois nas bandejas plásticas, onde foi obtido o menor comprimento de raiz $(0,7 \mathrm{~cm})$, as bases das estacas plantadas ficavam próximas ao fundo destes recipientes, impedindo assim, o crescimento geotrópico positivo das raízes. NICOLOSO et al. (2000) observaram o efeito do recipiente no comprimento de raízes em mudas de grápia (Apuleia leiocarpa) e relataram que os maiores comprimentos ocorreram nos recipientes de maior altura. $\mathrm{O}$ maior comprimento de raiz ocorreu com o substrato vermiculita $(3,4 \mathrm{~cm})$, porém foi estatisticamente equivalente aos substratos areia $(2,6 \mathrm{~cm})$, areia + vermiculita $(2,5 \mathrm{~cm})$ e vermiculita + casca de arroz carbonizada $(2,0 \mathrm{~cm})$. STUMPT et al. (1999), estudando o enraizamento de estacas de uma conífera (Chamaecyparis lawsoniana Parl) em cinco substratos com uso de IBA, observaram que houve tendência de que, com o aumento da porosidade total, espaço de aeração e água facilmente disponível no substrato, haja aumento do comprimento de raiz. Os menores resultados obtidos com casca de arroz carbonizada $(0,8 \mathrm{~cm})$ pode ser explicado pela baixa capacidade de retenção de água e pela baixa agregação com as raízes deste substrato. Verifica-se na figura 1
Tabela 3 - Comprimento de raiz $(\mathrm{cm})$ em estacas lenhosas de pessegueiro cv. Okinawa. Médias em função da interação entre os fatores recipiente e substrato. FCA/UNESP, Botucatu, 2001.

\begin{tabular}{lccccccc}
\hline & Ar & Ver & CC & Ar+Ver & Ar+CC & Ver+CC & Médias \\
\hline BPl & $0,7 \mathrm{bAB}$ & $3,7 \mathrm{aA}$ & $1,0 \mathrm{aAB}$ & $0,1 \mathrm{bB}$ & $0 \mathrm{bB}$ & $0 \mathrm{bB}$ & 0,7 \\
$\mathrm{BPe}$ & $2,1 \mathrm{abA}$ & $2,7 \mathrm{aA}$ & $1,4 \mathrm{aA}$ & $2,5 \mathrm{bA}$ & $3,3 \mathrm{aA}$ & $1,6 \mathrm{bA}$ & 2,2 \\
$\mathrm{Sac}$ & $5,9 \mathrm{aA}$ & $4,1 \mathrm{aA}$ & $0 \mathrm{aB}$ & $6,5 \mathrm{aA}$ & $0,7 \mathrm{abB}$ & $5,0 \mathrm{aA}$ & 3,3 \\
Médias & 2,6 & 3,4 & 0,8 & 2,5 & 1,1 & 2,0 & \\
$\mathrm{CV}(\%)$ & & & & 45,3 & & & \\
\hline
\end{tabular}

Médias seguidas por letras distintas, minúsculas na mesma coluna e maiúsculas na mesma linha, diferem entre si pelo teste Duncan, em nível de $5 \%$ de significância. BPl - bandeja plástica, BPe - bandeja de poliestireno expandido, Sac - saco plástico, Ar - areia, Ver - vermiculita, CC - casca de arroz carbonizada. 


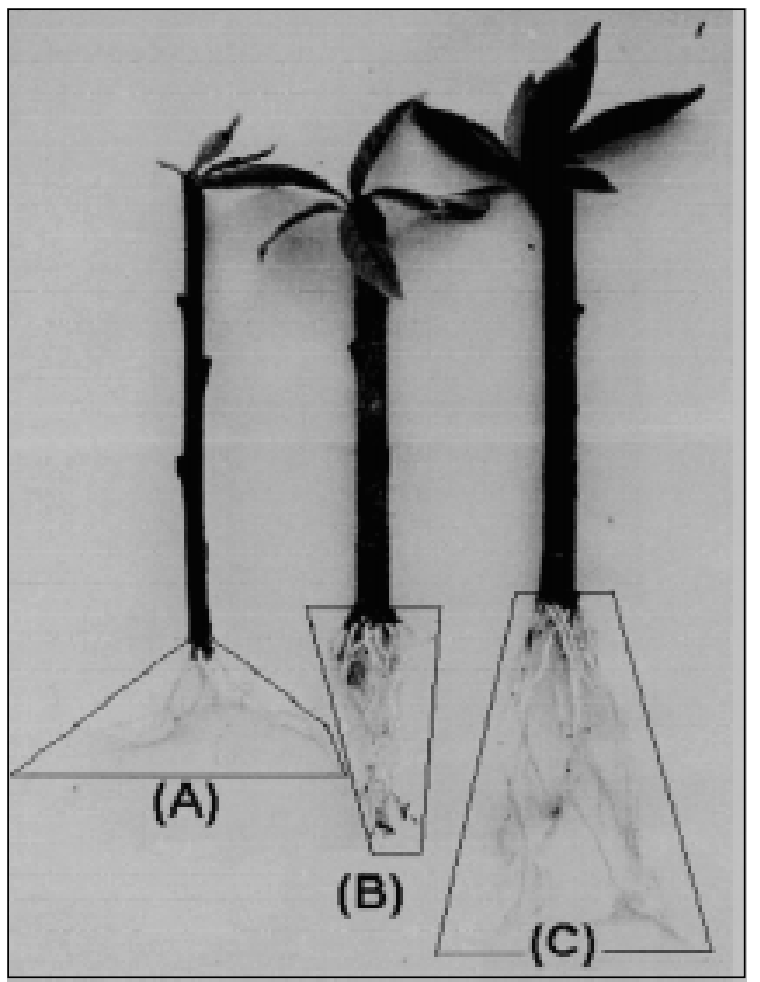

Figura 1 - Efeito do tipo de recipiente no crescimento das raízes adventícias de estacas de ramos lenhosos de pessegueiro $\mathrm{cv}$. Okinawa utilizando-se como substrato a vermiculita. (A) - estaca enraizada em bandeja plástica, (B) - estaca enraizada em bandeja de poliestireno expandido, $(\mathrm{C})$ - estaca enraizada em saco plástico. FCA/UNESP, Botucatu, 2001.

que os recipientes influenciaram na conformação do sistema radicular das estacas, pois na bandeja de poliestireno expandido (Figura 1-B) e no saco plástico (Figura 1-C) houve maior crescimento e melhor conformação das raízes, já para bandeja plástica (Figura 1-A) houve tendência de crescimento na horizontal, o que poderia dificultar as etapas posteriores ao enraizamento na propagação por estaca. Para a interação recipiente e substrato, observa-se na Tabela 3 que o maior comprimento de raiz foi obtido em saco plástico com areia + vermiculita $(6,5 \mathrm{~cm})$, embora tenha sido estatisticamente igual à areia $(5,9 \mathrm{~cm})$, vermiculita $(4,1 \mathrm{~cm})$ e vermiculita + casca de arroz carbonizada $(5,0 \mathrm{~cm})$.

AL-SACUI \& ANDERSON (1996) obtiveram em estacas de roseira (Rosa centifolia) maior número e comprimento de raízes, quando utilizaram como substrato turfa+perlita e atribuíram a estes resultados à melhor retenção de água e à boa aeração do substrato. Isto poderia explicar os melhores resultados de número e comprimento de raízes obtidos com vermiculita, areia e areia + vermiculita no presente trabalho.

\section{CONCLUSÕES}

As melhores porcentagens de enraizamento são obtidas com os substratos vermiculita $(20,5 \%)$ e a areia $(11,8 \%)$.

Os maiores porcentuais de enraizamento ocorrem nos recipientes saco plástico $(12,6 \%)$ e bandeja de poliestireno expandido $(10,0 \%)$.

Em geral, os recipientes bandeja de poliestireno expandido e saco plástico, bem como os substratos areia, vermiculita, e areia+vermiculita, proporcionam os melhores resultados de brotação, número de raízes e comprimento de raiz.

\section{REFERÊNCIAS BIBLIOGRÁFICAS}

AgrianUal. Anuário da Agricultura Brasileira. São Paulo : FNP Consultoria \& Comércio, 1999. 546p.

AGRIAnUAl. Anuário da Agricultura Brasileira. São Paulo : FNP Consultoria \& Comércio, 2001. 545p.

AVERY, J.D.; BEYL, C.B. Propagation of peach cuttings using foam cubes. HortScience, Alexandria, v.26, n.9, p.1152$1154,1991$.

AL-SACRI, F.; ALDERSON, P.G. Effects of IBA, cuttings type and rooting media on rooting of Rosa centifolia. The Journal of Horticultural Science, Loughborough, Leics, v.71, n.5, p.729-737, 1996.

CHALFUN, N.N.J. et al. Efeito do anelamento e diferentes dosagens do ácido indolbutírico na propagação de estacas caulinares do pessegueiro "Okinawa". Revista Brasileira de Fruticultura, Cruz das Almas, v.16, n.1, p.119-126, 1994.

CHAlfun, N.N.J.; HOFFMANN, A. Propagação do pessegueiro e da ameixeira. Informe Agropecuário, Belo Horizonte, v.18, n.189, p.23-29, 1997.

DUTRA, L.F.; KERSTEN, E. Efeito do substrato e da época de coleta de ramos no enraizamento de estacas de ameixeira (Prunus salicina Lindl). Ciência Rural, Santa Maria, v.26, n.3, p.361-366, 1996.

FACHINELlO, J.C. et al. Propagação de plantas frutíferas de clima temperado. Pelotas : UFPEL, 1995. 179p.

HARTMANN, H.T. et al. Plant propagation: principles and practices. 6.ed. New Jersey : Prentice Hall, 1997. 770p.

HOFFMANN, A. de et al. Fruticultura comercial: propagação de plantas frutíferas. Lavras : UFLA/FAEPE, 1996. $319 \mathrm{p}$.

MESÉN, F.; NEWTON, A.C.; LEAKEY, R.R.B. Vegetative propagation of Cordia alliodora (Ruiz \& Pavon) Oken: the effects of IBA concentration, propagation medium and cutting 
origin. Forest Ecology and Management, Amsterdam, v.92, n.1-3, p.45-54, 1997.

KLEIN, J.D.; COHEN, S.; HEBBE, Y. Seasonal variation in rooting ability of myrtle (Myrtus communis L.) cuttings. Scientia Horticulture, Amsterdam, v.83, n.1, p.71-76, 2000.

NACTHIGAL, J.C.; PEREIRA, F.M. Propagação do pessegueiro (Prunus pérsica (L.) Batsch) cv. Okinawa por meio de estacas herbáceas em câmara de nebulização em Jaboticabal - SP. Revista Brasileira de Fruticultura, Jaboticabal, v.22, n.2, p.208-212, 2000.

NICOLOSO, F.T. et al. Recipientes e substratos na produção de mudas de Maytenus ilicifolia e Aluleia leiocarpa. Ciência Rural, Santa Maria, v.30, n.6, p.987-992, 2000.

OFORI, D.A. et al. Vegetative propagation of Milicia excelsa by leaf stem cuttings: effects of auxin concentration, leaf area and rooting medium. Forest Ecology and Management, Amsterdam, v.84, n.1-3, p.39-48, 1996.
STUMPF, E.R.T.; GROLLI, P.R.; SILVA, J.A.G. da. Enraizamento de estacas de Chamaecyparis lawsoniana Parl. em cinco substratos com uso de ácido indolbutírico. Ciência Rural, Santa Maria, v.29, n.2, p.987-992, 2000.

TOFANELLI, M.B.D. et al. Enraizamento de estacas lenhosas e semilenhosas de cultivares-copa de pessegueiro em diferentes concentrações de ácido indolbutírico. Revista Brasileira de Fruticultura, Cruz das Almas, v.19, n.2, p.259-265, 1997.

TOFANELLI, M.B.T. Enraizamento de estacas lenhosas e semilenhosas de cultivares de pessegueiro em diferentes concentrações de ácido indolbutírico. 1999. 87f. Dissertação (Mestrado em Agronomia) - Curso de PósGraduação em Agronomia, Universidade Federal de Lavras.

TONIETTO, A.; DUTRA, L.F.; KERSTEN, E. Influência do ácido indolbutírico e ethephon no enraizamento de estacas de pessegueiro (Prunus persica (L.) Batsch). Ciência Rural, Santa Maria, v.27, n.4, p.567-569, 1997. 